\title{
DYE SENSITIZED SOLAR CELL (DSSC) PERFORMANCE ANALYSIS BASED ON SERIES CIRCUIT
}

\author{
M.F.L. Abdullah ${ }^{1, a^{*}}$, Anika Zafiah M.Rus ${ }^{2, b}$ \\ ${ }^{1}$ Faculty of Electrical \& Electronic Engineering \\ ${ }^{2}$ Sustainable Polymer Engineering, \\ Advanced Manufacturing and Materials Center, \\ University Tun Hussein Onn Malaysia \\ afaiz@uthm.edu.my, bafiah@uthm.edu.my,
}

Keywords: Dye Sensitized, Solar Cell,

\begin{abstract}
Solar power system is one of the renewable sources that will be used to produce electricity because of its characteristics such as consumed free source of sun light, less maintenance needed for the system and free of charge for usage electricity. One of the main disadvantages is the initial cost of the equipment used to harness the suns energy especially the cost of solar panel. In Malaysia, the cost of solar panel are relatively high because the solar panel are imported from overseas and the materials used in existing solar panel is very expensive. Therefore the proposed solar cells that will be used is natural dye sensitized with photovoltaic material. The scope of this research is to full fill the demand of low cost and to abundance, renewable material that could be used for energy conversion solar cell. The circuit connections of solar cells are in series and the performance of the dye sensitized cells would be based on the intensity of the sunlight illumination. The measurement of solar cell are conducted using 10 dye sensitizied cells connected in series circuit arrangement and the performance for this design are evaluated based on the generated potential (V) upon sunlight illumination at noon and evening for certain period of time. The result obtained from this research shows that the performance of series circuit connection of the dye sensitized solar cell is comparable with the silicon solar cell.
\end{abstract}

\subsection{Introduction}

Energy from sunlight could be used to generate current using a solar cells. Therefore solar energy system is one of the renewable energy that will be used to reduced the earth energy crisis. Solar cells are usually made from silicon, the same material used for transistors and integrated circuits. The advantages of the crystalline silicon solar cell include its high efficiency rate of $14-22 \%$ and the high stability of silicon.[9] These cells are established as the technology leader of technology. Although crystalline silicon has many advantages it also has some flaws. It is very expensive to produce and has a low absorption coefficient.The solar cells made from the dyesensitized will solve this issue because its considerably cheaper to be manufactured.[10][14] Although the silicon solar cells are currently more efficient, the dye sensitized solar cells are considerably cheaper to manufacture. In future it is expected to see further gains in the efficiency of dye-sensitized solar cells. [15]

\subsection{Theoretical review}

\subsection{Overview of dye sensitized solar cell (DSSC)}

The dye sensitized solar cell (DSSC) has been around for a long time, but obtained only low conversion efficiencies, since a relatively thick layer of dye was used. Since the overall light absorption of a dye monolayer were low, limited the photocurrent efficiency with respect to the incident light to a value well below $1 \%$. Semiconductors in mesoporous membrane type film with a high surface area led to an efficient light absorption by attached sensitizers and resulted in intensely colored photo anodes. After the announcement of surprisingly high efficiencies by O'Regan and 
Grätzel in the early-1990s [4], this type of solar cell is under reinforced development aiming at large area and low cost solar cells [5].

\subsection{Past, present, and future of dye-sensitized solar cells}

DSSCs use an organic dye extracted from plants to imitate the manner in which plants and certain algae convert sunlight into energy. Though these solar cells are still in relatively early stages of development, they show great promise as an inexpensive alternative to costly silicon solar cells and an attractive candidate for a new renewable energy source. Michael Grätzel and Brian O'Regan invented "Dye-sensitized solar cells", also called "Grätzel cells", in 1991. Although the silicon based solar cells are currently more efficient, the dye-sensitized solar cells are considerably cheaper to manufacture. The overall efficiency of solar cells has for awhile been unable to get past what was the current peak efficiency of around 11 percent for cells using titanium dioxide.[3] Recently researchers at University of Washington have come up with a new technique that has been dubbed the popcorn ball method. When light hits the surface of the cells some of the light is reflected. The idea behind the popcorn ball effect is that by making a very large number of very tiny cells, the efficiency output of the solar cells can be double. It would take about 3500 of these microscopic cells to make up the width of a single piece of hair. Therefore when looking for alternative sources for electricity in the future, the possibilities of using dye-sensitized solar cells is an alternative option.[6][7][8] When the efficiency of the dye-sensitized solar cells is increased they will most likely replace the high priced solar cells on the market today.[11] Therefore, for an ac electrical power, to power ac designed appliances and for integration with an electricity grid,the dc current supplied by the photovoltaic modules is converted to ac power of appropriate frequency using an inverter.[1][2]

\subsection{Methodology}

This section explain in detail the five phase for implementation of this project. Phase 1 is the housing design of DSSC of an electrical circuit for 10 Dye sensitized solar cell (DSSC) or more in a series is arranged. The design DSSC housing is shown in Fig.2.
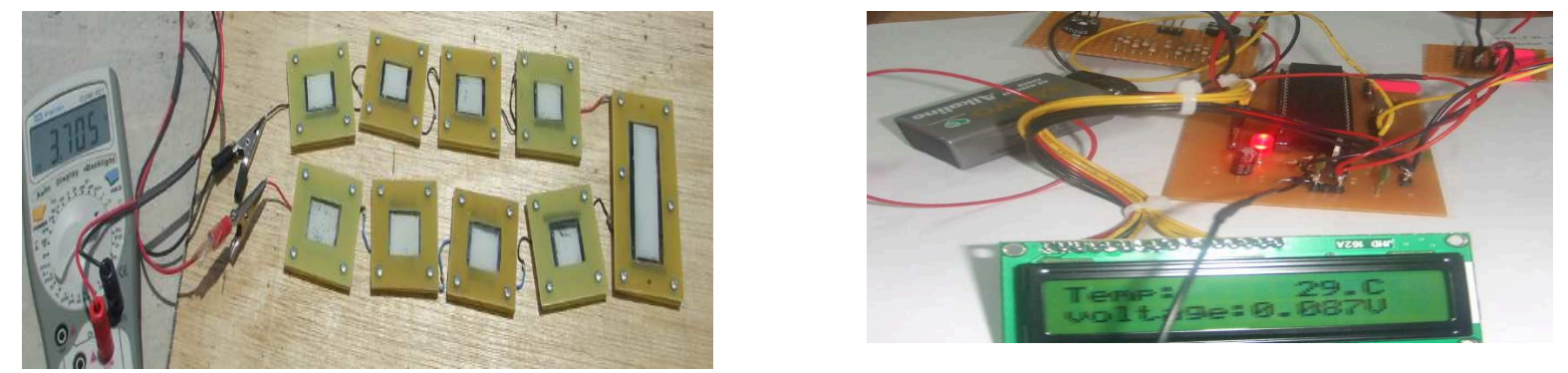

Fig.2: Design of DSSC housing and circuit to measure the voltage and temperature

Phase II is development of the tools to measure voltage and ambient temperature using microC Pro for PIC. C programming is written and then the program must be tested to check for any errors before uploaded into the PIC. The next process is to design the hardware for temperature sensor, PIC and driver circuit. The circuits are designed using PCB Wizard software. Temperature sensor LM 35 is used to detect the room temperature while PIC16F877A is the program chip to control the voltage and temperature. A LCD display is used to display the value of the actual room temperature and voltage. Fig. 3 shows the schematic diagram for this circuit.The process in Phase III is performed after the DSSC solar panels has been tested and confirm its functionality. The performance analysis is to measure the solar energy potential (V) generated upon sunlight illumination for a certain period of time in order to determine design stability and to measure sunlight intensity using Lux meter for comparison. DSSC solar panels require a large surface area 
so that the panels can be pointed towards the Sun. The more exposed surface area means more electricity can be converted from the light energy from the Sun. Phase IV discussed the performance analysis of the DSSC based on the potential,temperature and intensity sunlight illumination. The result Of DSSC when exposed to sunlight illumination for two condition at:
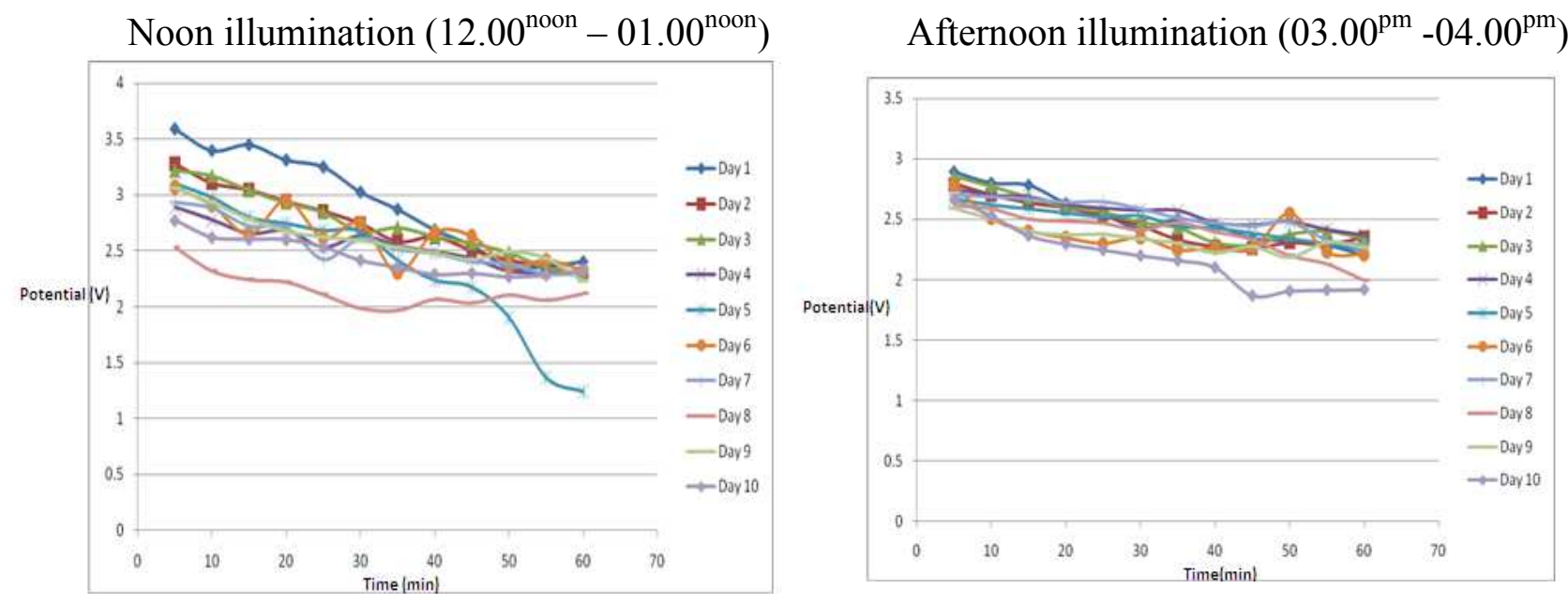

Fig. 4 : Graph of the potential (V) versus Time for housing DSSC upon sunlight illumination at noon and afternoon

Referring to the data that obtained from Fig. 4, shows that the results for ten days upon sunlight illumination at noon, the maximum value of potential is $3.593 \mathrm{~V}$ on day 1 while the minimum value is $1.240 \mathrm{~V}$ on day 5.The graph plotted remained stable until day 10. This is due to the evaporation of the electrolyte $\mathrm{KI}_{3}$ and dried by noon sunlight exposure. Figure 4 also, shows the results for ten days upon sunlight during afternoon, the maximum potential $(\mathrm{V})$ is $2.892 \mathrm{~V}$ on day 1 and the minimum potential value is 1.870 on day 10 . The intensity of sunlight are lower during thrafternoon which can also influence the results. Fig. figure The performance of DSSC when exposed to the sunlight illumination on day 6 at noon based on the temperature $\left({ }^{0} \mathrm{C}\right)$ and potential $(\mathrm{V})$. The maximum potential value is $2.782 \mathrm{~V}$ at $41^{\circ} \mathrm{C}$ and the minimum potential value is 2.382 at $34^{0} \mathrm{C}$. Overall, the potential is almost proportional with the ambient temperature.

\subsection{The efficiency of Dye sensitized solar cell (DSSC) Analysis}

\subsubsection{Power input measurement}

The solar cell performance is determined by its overall conversion efficiency ( $\mathrm{y}$ ) and incident photons to conversion efficiency (IPCE). Three parameters (Isc,Voc, and FF) are usually used to characterize solar cell outputs. The short-circuit current Isc, is obtained when the current flows freely through an external circuit that has no load or resistance. Voc corresponds to the energy difference between the Fermi level of the semiconductors and the level of the electrolyte redox couple. The maximum power is indicated by the area of the rectangle. The fill factor (FF) can be calculated from the maximum power point,which is quantitative measure of the device's quality defined by the square of the I-V curve as shown in Fig. 5. Input power is a result of the photons hitting the solar cell surface. Several processes can happen in order to attenuate the light reaching the material that absorbs the incoming light.

$$
\text { Power input }(\text { Pin })=\text { irradiance } \mathrm{x} \text { Area of cell }=\text { Ps } \mathrm{x} \text { A }
$$

Where Ps=1000 watt(theoretical value under sunlight illumination at noon) [13]. 


\subsubsection{Performance analysis of Dye sensitized solar cell (DSSC) upon sunlight illumination at noon.}

$$
\begin{aligned}
\text { Pin } & =((0.068 \times 0.018 \times 2 \text { units DSSC })+(0.018 \times 0.017 \times 8 \text { units DSSC })) \times 1000 \\
& =4.896 \text { watt }
\end{aligned}
$$

Table 1 :The graph voltage (V) versus current (A)

\begin{tabular}{|c|c|}
\hline $\mathrm{V}$ & $\mathrm{I}(\mathrm{A})$ \\
\hline 3.593 & 0 \\
\hline 3.399 & 0.5 \\
\hline 3.451 & 0.4 \\
\hline 3.315 & 0.8 \\
\hline 3.252 & 1.2 \\
\hline 3.026 & 1.6 \\
\hline 2.871 & 1.9 \\
\hline 2.688 & 2 \\
\hline 2.547 & 2 \\
\hline 2.352 & 2 \\
\hline 2.362 & 2 \\
\hline 2.401 & 2 \\
\hline 0 & 2 \\
\hline
\end{tabular}

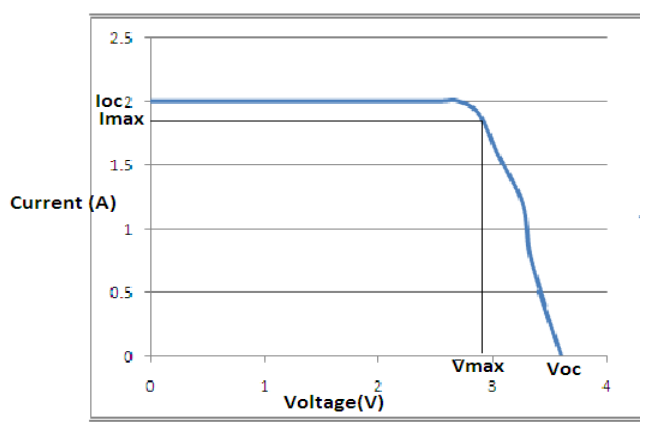

Fig. 8 :The I-V curve of a Dye sensitized solar cell under illumination

The performance of the commercial sillicon solar cell could reach up to $1.5 \%$ [13], but when comparing to the performance of the design DSSC solar cells samples only $0.000106 \%$. Therefore the main two problems for this low efficiency performance is related with the fabrication technique, where electrolyte $\mathrm{KI}_{3}$ that has been evaporated and dried up by the sunlight exposure [12]. A better design of DSSC could be to improve the design efficiency.In addition the lower current of the DSSC will also effect the efficiency of the DSSC.The lower of the current is because the resistance of DSSCis high.The resistances is approximately in Mega ohm. If the current of DSSC increases the efficiency will also increased.

\section{Conclusion}

Overall, the main goals for this research was successfully accomplished; to design the housing for 10 Dye sensitized solar cell (DSSC) or more in a series arrangement. Its performance can be analyze in terms of Dye sensitized solar cell (DSSC) energy potential (V) generated upon sunlight illumination at noon and afternoon for design stability determination and to measure the performance of Dye sensitized solar cell (DSSC) based on sunlight intensity using Lux meter.

\section{Acknowledgements}

The authors would like to thank Universiti Tun Hussein Onn Malaysia, Johor, and Malaysian Government for supporting this research under Fundamental Research Grant Scheme(Phase 1/2012), vot 1047.

\section{References}

[1] Haiying Wan(2004).'Dye sensitized solar cells".Literature seminar

[2] Jenny Nelson(2003).’The physics of solar cells".Imperial College press

[3] T. B. Johansson et al (eds) (1993). "Renewable Energy -sources for fuels and electricity". Earthscan

[4] Messenger R. and Ventre J (2000).'Photovoltaic Systems Engineering”.CRCPress LLC, United States of America,. 
[5] Deo Prasad \& Mark Snow (2005).”Designing with solar power”.Earthscan.

[6] T. Kado, M. Yamaguchi, Y. Yamada and S. Hayase (Oct. 2003)."Low Temperature Preparation of Nano-porous TiO2 Layers for Plastic Dye Sensitized Solar Cells" .Chem.Lett., vol. 32, pp.1056-1057,.

[7] T. Miyasaka and Y. Kijitori (Nov. 2004). "Low-Temperature Fabrication of Dye-Sensitized Plastic Electrodes by Electrophoretic Preparation of Mesoporous TiO2 Layers". J. Electrochem. Soc., vol. 151, pp.A1767-1773,.

[8] M. Murayama, E. Yamazaki, N. Nishikawa, N.Hashimoto and T. Mori (Oct. 2006). "LowTemperature Fabrication of TiO2 Necking Electrode by Sol-Gel Method and its Application to Dye-Sensitized Solar Cell”. Jpn. J. Appl.Phys., vol. 45, pp. 7917-7921,.

[9] E.L. Ralph. "High Effiency solar cell array System Trade-offs". Twenfy Fourth IEEE, PVSC, 1994, pp. $\sim 1998-2001$.

[10] Albert H.Zimmerman(2009)."Nickel Hydrogen Batteries-Principle and practice".Aerospace press. Lin (Feb. 2008). "High-performance stand-Alone photovoltaic generation system". IEEE Trans. Ind. Electron., vol.55,no. 1, pp. 240-250,

[11] Smestad, GP, Gratzel, M. (1998) "Demonstrating electron transfer and nanotechnology: A natural dye-sensitized nanochrystalline energy converter." Journal of Chemical Education, 75 (6), 752-756.

[12] "Solar cell:from sunlight to electricity" retrieved on 24 January,2010 from world wide Web.lboro.ac.uk/departments/cm/business.pdf

[13] 'Solar E-card photovoltaic" retrieved on 29 January ,2010 from world wide Web;pivotryconsulting.com/download/epk/sunecardphotovoltaicpdf

[14] Anika ZafiahM. Rus, NurMunirah Abdullah, and M. F. L. Abdullah“ Characterization and Treatment of Titanium Dioxide via Ultrasonic Process with Melastoma malabathricum as Sustainable Sensitizer for Photovoltaic Solar Cell" Journal of Chemistry, Hindawi Publishing Corporation, Volume 2013, Article ID 251741, 10 pages.

[15] Simon Mathew et al " Dye-sensitized solar cells with 13\% efficiency achieved through the molecular engineering of porphyrin sensitizers" Nature ChemistryVolume: 6,Pages: pg : 242-247Year published: (2014)DOI: 